\title{
Venous Resection in Pancreatic Ductal Adenocarcinoma: Impact of Surgical Experience on Early Postoperative Courses
}

\author{
THEOPHILE GUILBAUD ${ }^{1}$, OLIVIER TURRINI ${ }^{1}$, CORALIE LEMOINE ${ }^{2}$, YVES PATRICE LE TREUT ${ }^{3}$, \\ MEHDI OUAISSI ${ }^{4}$, VINCENT MOUTARDIER $^{5}$ and JEAN ROBERT DELPERO ${ }^{1}$ \\ ${ }^{1}$ Department of Surgical Oncology, Institut Paoli-Calmettes, Marseille, France; \\ ${ }^{2}$ Self Perceived Health Assessment Research Unit and Department of Public health, \\ Aix-Marseille University, Marseille, France; \\ ${ }^{3}$ Department of Digestive Surgery and Liver Transplantation, La Timone Hospital, \\ Aix-Marseille University, Marseille, France; \\ ${ }^{4}$ Department of Digestive Surgery, La Timone Hospital, Aix-Marseille University, Marseille, France; \\ ${ }^{5}$ Department of Digestive Surgery, Nord Hospital, Aix-Marseille University, Marseille, France
}

\begin{abstract}
Background/Aim: The aim of this study was to determine the effects of surgical experience on early postoperative courses after pancreaticoduodenectomy (PD) with venous resection. Patients and Methods: From 2005 to 2014, 134 patients were analyzed, 62 and 72 patients were resected in periods 1 (2005-2009) and 2 (2010-2014) respectively; 115 and 19 patients underwent $P D$ with venous resection in high-and low-volume center groups respectively. Results: Of the entire cohort, mortality rate was $4 \%$. There were no significant differences between the two periods. In the low-volume center group, the mortality rate was increased $(21 \% v s .2 \%, p<0.01)$ and the mean length of hospital stay was longer $(25( \pm 27)$ days vs. $17( \pm 8)$ days, $p=0.04)$. The high-volume center group was the only independent protective factor regarding death $(O R=0.04,95 \% C I(0.01-0.38), p<0.01)$ and length of hospital stay (OR<0.01, 95\%CI (0.00-0.43), $p=0.03)$. Conclusion: Patients who present isolated venous invasion must be referred to high-volume centers for surgery.
\end{abstract}

Pancreatic ductal adenocarcinoma (PDAC) accounts for $10 \%$ of all digestive cancers (1). Only $15 \%$ of PDACs are amenable to curative therapy, consisting of complete surgical resection combined with adjuvant chemotherapy (2-6). Additionally, determining the resectability of tumors at such an early stage does not preclude rapid progression or

Correspondence to: Théophile Guilbaud, Department of Surgical Oncology, Institut Paoli-Calmettes, Marseille, France. Tel: +33 491223660, Fax: +33 491223550, e-mail: theo.guilbaud@gmail.com

Key Words: Pancreaticoduodenectomy, venous resection, highvolume center, surgical experience, mortality. dissemination, resulting from aggressive tumor biology once the diagnosis has been made (7). Between 20-30\% of PDACs considered resectable at imaging, are in fact locally advanced or unresectable at the time of exploratory laparotomy owing to locoregional progression or metastasis (8-10). The major goal of surgery is to achieve a radical resection (R0). The latter is achievable even in the presence of portal vein (PV) or superior mesenteric vein (SMV) invasion. The majority of patients with PV/SMV infiltration detected by initial staging (locally advanced disease) must undergo neoadjuvant therapy (6). However, for patients in whom isolated involvement of the PV/SMV was not detected at initial staging but was found intraoperatively, the optimal management is controversial; up-front surgery does not seem to be the appropriate strategy (11-13). During the last decade, there has been renewed interest in vascular resection for isolated involvement of the PV/SMV (PV/SMVresection) in PDAC; however, there have been conflicting results according to the postoperative course as well as the impact on survival. Some studies have reported comparable complications and survival rates between standard pancreaticoduodenectomy (PD) and PD with PV/SMVresection (14-20). Conversely, other studies have reported increased morbidity with no survival benefit for patients undergoing PD with PV/SMV-resection $(6,13,21-23)$. Moreover, there is strong evidence that a center's volume and team focus (surgeons, endoscopists, radiologists and pathologists) remain an important determinant of overall mortality, postoperative outcomes, in hospital length of stay and costs of pancreatic surgery (24-30). Nonetheless, the impact of either the experience of the team focused on vascular resection or hospital volume have not been clearly established for PV/SMV-resection associated with PD. 
The aim of this study was to determine the effects of the experience of teams focused on vascular resection and the center's volume on the early postoperative courses in patients undergoing PD with PV/SMV-resection for PDAC.

\section{Patients and Methods}

Design, setting, and patients. From January 2005 to December 2014, 134 patients underwent PD with PV/SMV-resection for PDAC at the Marseille University Hospital group associating four centers specializing in pancreatic surgery. Data were obtained by a retrospective review of a prospectively collected clinical database. Supplemental data for this study were obtained by office and electronic medical record reviews. To determine the impact of surgical experience and the center's volume on venous resection/reconstruction, we subsequently assessed two periods and two groups. Indeed, 2010 was a turning point for the four centers with team focused on pancreatic surgery. Thus, the first period spanned from 2005 to 2009 (62 PD with PV/SMVresection), and the second period started in 2010 until 2014 (72 $\mathrm{PD}$ with $\mathrm{PV} / \mathrm{SMV}$-resection). We also distinguished two centers who performed five or more PD with PV/SMV-resection per year (115 PD with PV/SMV resection were achieved in these two centers; the high volume center group) and the two others performed fewer than five procedures per year (19 PD with $\mathrm{PV} / \mathrm{SMV}$ resection were achieved in these two centers; the low volume center group). Patients with metastasis or carcinomatosis were excluded from the present study.

Preoperative evaluation. Pancreatic tumors were assessed using preoperative computed tomographic (CT) scans performed in the previous four weeks. Magnetic resonance imaging, endoscopic ultrasound and laparoscopy were performed on an individual patient basis according to the multidisciplinary team discussion. A pancreatic tumor was defined as locally advanced when there was $\mathrm{PV} / \mathrm{SMV}$ invasion, encasement or abutment of the superior mesenteric artery (SMA) or celiac trunk (12); these patients received neoadjuvant treatment according to center/physician preference. At restaging, patients who had isolated PV/SMV infiltration and in whom venous reconstruction was determined to be feasible underwent explorative laparotomy for resection. In patients with supposedly resectable PDAC at the initial staging and with isolated $\mathrm{PV} / \mathrm{SMV}$ involvement found intraoperatively, no standard treatment has been accepted; interruption of laparotomy and neoadjuvant treatment or up-front venous resection was performed according to surgeon/center preferences.

Surgical data. PD with PV/SMV-resection surgeries were performed by experienced surgeons who had executed a mean of 20 or more PDs per year, with or without venous resection. In two of the centers, a vascular surgeon was recruited during the surgery to perform the venous resection. PD with PV/SMV-resection surgeries were performed through a large transversal laparotomy. After a thorough abdominal exploration, an artery-first approach determined the status of the SMA margin before an irreversible step in the dissection was made (31). Subsequently, a Kocher maneuver was performed. All anatomic dissections, including the hepatoduodenal ligament, pancreatic neck transection, duodenojejunal flexure, uncinate process of the pancreas and mobilization of the infra pancreatic SMV, were performed before obtaining vascular control for venous resection. The pancreatic neck transection margin and common bile/hepatic duct transection margins were evaluated by frozen-section analysis, and additional tissue was resected to achieve negative margins at the two sites if the results were positive. Regional lymph nodes around the common hepatic artery, celiac trunk, hepatoduodenal ligament, as well as anterior and posterior pancreaticoduodenal areas were routinely dissected. Venous reconstruction was only performed after en-bloc resection of the head of the pancreas, duodenum, distal common bile duct, and retroperitoneal soft tissue margin were completed. Dissection of the right hemi circumference of the SMA to the right of the celiac trunk was required to obtain adequate medial clearance. In some cases, the section of the splenic vein from the right side of the PV gave privileged access to the right hemi circumference of the SMA, which made the dissection faster to perform, prior to the en-bloc removal of the pathological specimen with PV/SMV resection. The SMA was not routinely clamped; a simple venous suture was performed on patients undergoing lateral venous resection (LVR). The latter was performed transversally to ultimately avoid vein narrowing. If the transversal venous suture led to venous stenosis, a segmental venous resection (SVR) was performed. In the case of SVR, after mobilization of the mesenteric root, reconstruction was performed with a primary end-to-end anastomosis. Whenever a tension-free anastomosis was impossible despite complete mobilization of the mesenteric root, a venous or a prosthetic bypass was achieved. No curative anti-coagulation regimen was used postoperatively, except when a venous or a prosthetic bypass was achieved. In our study, a prophylactic anti-coagulation was the standard of care in the postoperative period, to prevent a venous thrombotic event. Extended resection was defined as a PD associated with any of the following organs involved in continuity: more than the distal half of the stomach; colon and/or mesocolon with relevant vascular structures of the transverse mesocolon (ileocolic, right, middle or left colic vessels); small bowel beyond the first segment of the jejunum; adrenal gland; kidney and/or its vasculature; and liver. The aim of this surgical procedure was to achieve a free margin resection.

Pathological examination. The collected data included tumor size and grading, lymphovascular and perineural invasion, and resection margin status. Tumors were graded according to the seventh edition of the American Joint Committee on Cancer staging manual (32). Serial slicing of the entire pancreatic head specimen was performed in a single axial plane according the Royal College of Pathologists and the Leeds Pathology Protocol guidelines $(33,34)$. The surgeon clearly identified the margins in the operative room with multicolor coded ink. The posterior margin was inked in yellow; the PV-SMV margin was inked in blue, and the SMA margin in red. The venous segment was clearly identified on the specimen. That way, large slices were obtained, allowing for a precise study of each inked margin. A positive margin was defined as a tumor present within $1.5 \mathrm{~mm}(35,36)$.

Outcomes. Postoperative mortality included all deaths occurring prior to hospital discharge or within 30 days of the surgery. Morbidity included all complications following surgery until discharge and/or readmission within 90 days and was graded according to the Dindo-Clavien classification. Severe morbidity included Dindo-Clavien grade 3 and 4. PSCs included postoperative 
pancreatic fistula (POPF), bile leak, postoperative hemorrhage, intra-abdominal abscess and delayed gastric emptying (DGE). POPF and hemorrhage were defined according to the International Study Group of Pancreatic Surgery (ISGPS), pancreatic stump leak included fistulas and fluid collections. Grades B and C POPF were defined as clinical relevant POPF. Bile leak was defined as a bilious drainage from drains or bile collection requiring drainage. DGE was defined and classified based on the ISGPS. Duration of gastric decompression and oral intake were at the discretion of the surgical team. The length of hospital stay was calculated as the number of days from surgery to the date of discharge, and the 90 days readmission rate was noted.

Statistical analysis. Continuous variables are expressed as means \pm standard deviation (SD), categorical variables are expressed as numbers and percentages. Differences between periods and groups in terms of demographic characteristics, procedures, morbidity, and mortality were measured using a chi-squared test or Fisher's exact test for categorical data and Student's $t$-test for continuous data, as appropriate. The whole population was used in the primary analysis. A descriptive analysis was performed. All variables with a $p$-value $<0.05$ were included in the multivariate model. A $p$-value $<0.05$ was considered to be significant. The analysis was performed using R Studio version 0.99.486.

\section{Results}

Clinical characteristics, surgery and postoperative outcomes. Clinicopathological characteristics, surgery and postoperative outcomes are summarized in Table I. Among the 134 patients who underwent PD with PV/SMV-resection for PDAC, 44 $(33 \%)$ received a neoadjuvant therapy, and 68 (51\%) underwent preoperative biliary stenting. Mean tumor size was $35 \mathrm{~mm}( \pm 17 \mathrm{~mm})$, and the $\mathrm{R} 1$ resection rate and $\mathrm{N} 1$ status rate were $60 \%$ and $69 \%$, respectively. Sixty patients (45\%) had histological venous wall invasion.

Seventy-seven percent of patients $(n=103)$ underwent SVR; the main venous reconstruction was an end-to-end venous anastomosis. Total venous clamping was necessary in $84 \%$ of patients $(n=112)$, and arterial clamping of the SMA was associated with total venous clamping in $14 \%$ of patients $(n=19)$. The mean operative time was 469 minutes $( \pm 166$ minutes $)$, and $20 \%$ of patients $(n=27)$ underwent intraoperative blood transfusion. According to the postoperative outcomes, the mortality and severe morbidity (i.e. Clavien-Dindo grade 3 or 4$)$ rates were $4 \%(n=6)$ and $30 \%(n=40)$, respectively. All deaths were secondary to multi-visceral and cardiac failure in patients who experienced grade $\mathrm{C}$ POPF and postoperative hemorrhage. Clinical relevant POPF (grade $\mathrm{B} / \mathrm{C}$ ) occurred in $25 \%$ of patients $(n=33), 8 \%$ of patients $(n=11)$ had postoperative hemorrhage. Eight patients $(6 \%)$ underwent relaparotomy for early postoperative hemorrhage or drainage of an intraabdominal collection. DGE occurred in $44 \%$ of patients $(\mathrm{n}=59)$. The mean length of hospital stay was 19 days $( \pm 13$ days), and the 90-day readmission rate was $16 \%(n=21)$.
Table I. Demographics, procedure characteristics, histopathological findings and postoperative outcomes.

\begin{tabular}{|c|c|c|}
\hline \multirow[b]{2}{*}{ Characteristics } & \multicolumn{2}{|c|}{ No of patients } \\
\hline & & \\
\hline $\mathrm{n}$ & 134 & \\
\hline Female & 70 & $(52 \%)$ \\
\hline Age (years), mean $( \pm S D)$ & 65 & $( \pm 10)$ \\
\hline Neoadjuvant therapy & 44 & $(33 \%)$ \\
\hline Chemotherapy & 42 & $(31 \%)$ \\
\hline Radiotherapy & 24 & $(18 \%)$ \\
\hline Folfirinox & 20 & $(15 \%)$ \\
\hline Biliary stenting & 68 & $(51 \%)$ \\
\hline \multicolumn{3}{|l|}{ Histopathology } \\
\hline Tumoral size $(\mathrm{mm})$, mean $( \pm \mathrm{SD})$ & 35 & $( \pm 17)$ \\
\hline N1 status & 93 & $(69 \%)$ \\
\hline R1 status & 81 & $(60 \%)$ \\
\hline Lymph nodes analysed $(n)$, mean $( \pm S D)$ & 17 & $( \pm 8)$ \\
\hline Lymph nodes involved $(\mathrm{n})$, mean $( \pm \mathrm{SD})$ & 2 & $( \pm 3)$ \\
\hline Lymph nodes ratio, mean $( \pm \mathrm{SD})$ & 0.15 & $( \pm 0.16)$ \\
\hline Perineural invasion & 103 & $(77 \%)$ \\
\hline Venous wall invasion & 60 & $(45 \%)$ \\
\hline \multicolumn{3}{|l|}{ Surgical data } \\
\hline Operative time $(\mathrm{min})$, mean $( \pm \mathrm{SD})$ & 469 & $( \pm 166)$ \\
\hline Extended resection & 26 & $(19 \%)$ \\
\hline Soft pancreatic gland & 28 & $(21 \%)$ \\
\hline MPD stenting & 42 & $(31 \%)$ \\
\hline Pancreaticojejunostomy & 111 & $(83 \%)$ \\
\hline Pancreaticogastrostomy & 23 & $(17 \%)$ \\
\hline LVR & 31 & $(23 \%)$ \\
\hline SVR & 103 & $(77 \%)$ \\
\hline Total venous clamping & 112 & $(84 \%)$ \\
\hline Venous clamping duration $(\mathrm{min})$, mean $( \pm \mathrm{SD})$ & 19 & $( \pm 10)$ \\
\hline Arterial clamping & 19 & $(14 \%)$ \\
\hline Length of venous resection $(\mathrm{mm})$, mean $( \pm \mathrm{SD})$ & 21 & $( \pm 9)$ \\
\hline Autologous venous graft & 2 & $(1 \%)$ \\
\hline Prosthetic graft & 3 & $(2 \%)$ \\
\hline Blood transfusion & 27 & $(20 \%)$ \\
\hline Blood transfusion units $\geq 2$ & 21 & $(16 \%)$ \\
\hline \multicolumn{3}{|l|}{ Postoperative outcomes } \\
\hline Overall morbidity & 85 & $(63 \%)$ \\
\hline Severe morbidity & 40 & $(30 \%)$ \\
\hline Mortality & 6 & $(4 \%)$ \\
\hline PSCs & 71 & $(53 \%)$ \\
\hline Clinical relevant POPF & 33 & $(25 \%)$ \\
\hline Bile leak & 3 & $(2 \%)$ \\
\hline Hemorrhage & 11 & $(8 \%)$ \\
\hline DGE & 59 & $(44 \%)$ \\
\hline Relaparotomy & 8 & $(6 \%)$ \\
\hline Length of hospital stay (day), mean $( \pm \mathrm{SD})$ & 19 & $( \pm 13)$ \\
\hline 90 days readmission & 21 & $(16 \%)$ \\
\hline
\end{tabular}

MPD: Main pancreatic duct; LVR: lateral venous resection; SVR: segmental venous resection; PSCs: pancreatic specific complications; POPF: postoperative pancreatic fistula; DGE: delayed gastric empty.

Impact of the experience of the team focused on vascular resection (comparison of the two periods). Univariate analyses between period 1 (2005-2009) and period 2 (2010-2014) are summarized in Table II. The preoperative biliary stenting rate 
Table II. Demographics, procedure characteristics, histopathological findings and postoperative outcomes according to periods.

\begin{tabular}{|c|c|c|c|c|c|}
\hline & \multicolumn{2}{|c|}{ 2005-2009 } & \multicolumn{2}{|c|}{$2010-2014$} & $p$-Values \\
\hline \multicolumn{6}{|l|}{ Characteristics } \\
\hline $\mathrm{n}$ & 62 & & 72 & & \\
\hline Female & 26 & $(42 \%)$ & 42 & $(58 \%)$ & 0.24 \\
\hline Age (years), mean $( \pm \mathrm{SD})$ & 63 & $( \pm 10)$ & 65 & $( \pm 12)$ & 0.70 \\
\hline Neoadjuvant therapy & 18 & $(29 \%)$ & 26 & $(36 \%)$ & 0.46 \\
\hline Chemotherapy & 18 & $(29 \%)$ & 26 & $(36 \%)$ & 0.46 \\
\hline Radiotherapy & 17 & $(27 \%)$ & 7 & $(10 \%)$ & 0.01 \\
\hline Folfirinox & 0 & $(0 \%)$ & 20 & $(28 \%)$ & $<0.01$ \\
\hline Biliary stenting & 25 & $(40 \%)$ & 43 & $(60 \%)$ & 0.04 \\
\hline \multicolumn{6}{|l|}{ Histopathology } \\
\hline Tumoral size $(\mathrm{mm})$, mean $( \pm \mathrm{SD})$ & 35 & $( \pm 15)$ & 34 & $( \pm 18)$ & 0.79 \\
\hline N1 status & 42 & $(68 \%)$ & 51 & $(71 \%)$ & 0.71 \\
\hline $\mathrm{R} 1$ status & 39 & $(63 \%)$ & 42 & $(58 \%)$ & 0.60 \\
\hline Lymph nodes analysed $(\mathrm{n})$, mean $( \pm \mathrm{SD})$ & 17 & $( \pm 9)$ & 16 & $( \pm 7)$ & 0.75 \\
\hline Lymph nodes involved $(\mathrm{n})$, mean $( \pm \mathrm{SD})$ & 2 & $( \pm 3)$ & 3 & $( \pm 3)$ & 0.77 \\
\hline Lymph nodes ratio, mean $( \pm \mathrm{SD})$ & 0,13 & $( \pm 0.13)$ & 0,16 & $( \pm 0.18)$ & 0.19 \\
\hline Perineural invasion & 42 & $(68 \%)$ & 61 & $(85 \%)$ & 0.02 \\
\hline Venous wall invasion & 32 & $(52 \%)$ & 28 & $(39 \%)$ & 0.16 \\
\hline \multicolumn{6}{|l|}{ Procedure data } \\
\hline Operative time (min), mean $( \pm \mathrm{SD})$ & 426 & $( \pm 168)$ & 506 & $( \pm 157)$ & $<0.01$ \\
\hline Extended resection & 19 & $(31 \%)$ & 7 & $(10 \%)$ & $<0.01$ \\
\hline Soft pancreatic gland texture & 16 & $(26 \%)$ & 12 & $(17 \%)$ & 0,21 \\
\hline MPD stenting & 17 & $(27 \%)$ & 25 & $(35 \%)$ & 0.45 \\
\hline Pancreaticojejunostomy & 50 & $(81 \%)$ & 61 & $(85 \%)$ & 0.65 \\
\hline Pancreaticogastrostomy & 12 & $(19 \%)$ & 11 & $(15 \%)$ & \\
\hline LVR & 15 & $(24 \%)$ & 16 & $(22 \%)$ & 0.84 \\
\hline SVR & 47 & $(76 \%)$ & 56 & $(78 \%)$ & \\
\hline Total venous clamping & 51 & $(82 \%)$ & 61 & $(85 \%)$ & 0.82 \\
\hline Venous clamping duration $(\min )$, mean $( \pm \mathrm{SD})$ & 19 & $( \pm 9)$ & 19 & $( \pm 11)$ & 0.92 \\
\hline Arterial clamping & 10 & $(16 \%)$ & 9 & $(13 \%)$ & 0.62 \\
\hline Length of venous resection $(\mathrm{mm})$, mean $( \pm \mathrm{SD})$ & 18 & $( \pm 7)$ & 23 & $( \pm 10)$ & 0.11 \\
\hline Autologous venous graft & 0 & $(0 \%)$ & 2 & $(3 \%)$ & 0.50 \\
\hline Prosthetic graft & 1 & $(2 \%)$ & 2 & $(3 \%)$ & 1.00 \\
\hline Blood transfusion & 17 & $(27 \%)$ & 10 & $(14 \%)$ & 0.06 \\
\hline Blood transfusion units $\geq 2$ & 13 & $(21 \%)$ & 8 & $(11 \%)$ & 0.15 \\
\hline \multicolumn{6}{|l|}{ Overall postoperative outcomes } \\
\hline Overall morbidity & 39 & $(63 \%)$ & 46 & $(64 \%)$ & 1.00 \\
\hline Severe morbidity & 23 & $(37 \%)$ & 17 & $(24 \%)$ & 0.13 \\
\hline Mortality & 4 & $(6 \%)$ & 2 & $(3 \%)$ & 0.41 \\
\hline PSCs & 37 & $(60 \%)$ & 34 & $(47 \%)$ & 0.17 \\
\hline Clinical relevant POPF & 17 & $(27 \%)$ & 16 & $(22 \%)$ & 0.55 \\
\hline Bile leak & 3 & $(5 \%)$ & 0 & $(0 \%)$ & 0.10 \\
\hline Hemorrhage & 5 & $(8 \%)$ & 6 & $(8 \%)$ & 0.96 \\
\hline DGE & 31 & $(50 \%)$ & 28 & $(39 \%)$ & 0.22 \\
\hline Relaparotomy & 6 & $(10 \%)$ & 2 & $(3 \%)$ & 0.14 \\
\hline Length of hospital stay (day), mean $( \pm \mathrm{SD})$ & 19 & $( \pm 10)$ & 19 & $( \pm 14)$ & 0.99 \\
\hline 90 days readmission & 10 & $(16 \%)$ & 11 & $(15 \%)$ & 1.00 \\
\hline
\end{tabular}

MPD: Main pancreatic duct; LVR: lateral venous resection; SVR: segmental venous resection; PSCs: pancreatic specific complications; POPF: postoperative pancreatic fistula; DGE: delayed gastric empty.

was higher in period 2 when compared to period $1(60 \%$ and $40 \%, p=0.04)$. There were no significant differences between the two periods according to the type of venous resection (i.e. LVR or SVR) and the intraoperative blood transfusion rate. The mean operative time was longer in period $2(506( \pm 157)$ minutes and $426( \pm 168)$ minutes, $p<0.01)$. According to the histopathological findings, only the perineural invasion rate was significantly higher in period 2 than in period $1(85 \%$ and $68 \%, p=0.02)$. In terms of the postoperative course, no significant differences were noted between the two periods. 
Table III. Demographics, procedure characteristics, histopathological findings and postoperative outcomes according to volume center groups.

\begin{tabular}{|c|c|c|c|c|c|}
\hline \multirow[b]{2}{*}{ Characteristics } & \multicolumn{2}{|c|}{ High-volume center } & \multicolumn{2}{|c|}{ Low-volume center } & \multirow[t]{2}{*}{$p$-Values } \\
\hline & & & & & \\
\hline $\mathrm{n}$ & 115 & & 19 & & \\
\hline Female & 55 & $(48 \%)$ & 10 & $(53 \%)$ & 0.67 \\
\hline Age (years), mean $( \pm \mathrm{SD})$ & 66 & $( \pm 9)$ & 63 & $( \pm 4)$ & 0.40 \\
\hline Neoadjuvant therapy & 39 & $(34 \%)$ & 5 & $(26 \%)$ & 0.61 \\
\hline Chemotherapy & 38 & $(33 \%)$ & 4 & $(21 \%)$ & 0.42 \\
\hline Radiotherapy & 22 & $(19 \%)$ & 2 & $(11 \%)$ & 0.52 \\
\hline Folfirinox & 18 & $(16 \%)$ & 2 & $(11 \%)$ & 0.74 \\
\hline Biliary stenting & 60 & $(52 \%)$ & 8 & $(42 \%)$ & 0.47 \\
\hline \multicolumn{6}{|l|}{ Histopathology } \\
\hline Tumoral size $(\mathrm{mm})$, mean $( \pm \mathrm{SD})$ & 35 & $( \pm 17)$ & 31 & $( \pm 11)$ & 0.28 \\
\hline N1 status & 79 & $(69 \%)$ & 14 & $(74 \%)$ & 0.79 \\
\hline R1 status & 71 & $(62 \%)$ & 10 & $(53 \%)$ & 0.46 \\
\hline Lymph nodes analysed $(n)$, mean $( \pm S D)$ & 17 & $( \pm 8)$ & 14 & $( \pm 7)$ & 0.11 \\
\hline Lymph nodes involved $(n)$, mean $( \pm S D)$ & 2 & $( \pm 3)$ & 3 & $( \pm 4)$ & 0.71 \\
\hline Lymph nodes ratio, mean $( \pm \mathrm{SD})$ & 0,14 & $( \pm 0.14)$ & 0,19 & $( \pm 0.23)$ & 0.15 \\
\hline Perineural invasion & 94 & $(82 \%)$ & 9 & $(47 \%)$ & $<0.01$ \\
\hline Venous wall invasion & 50 & $(43 \%)$ & 10 & $(53 \%)$ & 0.47 \\
\hline \multicolumn{6}{|l|}{ Surgical data } \\
\hline Operative time (min), mean $( \pm \mathrm{SD})$ & 481 & $( \pm 172)$ & 397 & $( \pm 108)$ & $<0.01$ \\
\hline Extended resection & 25 & $(22 \%)$ & 1 & $(5 \%)$ & 0.12 \\
\hline Soft pancreatic gland & 18 & $(16 \%)$ & 10 & $(53 \%)$ & $<0.01$ \\
\hline MPD stenting & 37 & $(32 \%)$ & 5 & $(26 \%)$ & 0.79 \\
\hline Pancreaticojejunostomy & 97 & $(84 \%)$ & 18 & $(95 \%)$ & 0.19 \\
\hline Pancreaticogastrostomy & 22 & $(19 \%)$ & 1 & $(5 \%)$ & \\
\hline LVR & 21 & $(18 \%)$ & 10 & $(53 \%)$ & $<0.01$ \\
\hline SVR & 94 & $(82 \%)$ & 9 & $(47 \%)$ & \\
\hline Venous clamping & 103 & $(90 \%)$ & 9 & $(47 \%)$ & $<0.01$ \\
\hline Venous clamping duration $(\mathrm{min})$, mean $( \pm \mathrm{SD})$ & 19 & $( \pm 10)$ & 25 & $( \pm 7)$ & 0.42 \\
\hline Arterial clamping & 19 & $(17 \%)$ & 0 & $(0 \%)$ & 0.07 \\
\hline Length of venous resection $(\mathrm{mm})$, mean $( \pm \mathrm{SD})$ & 21 & $( \pm 9)$ & 18 & $( \pm 10)$ & 0.58 \\
\hline Autologous venous graft & 2 & $(2 \%)$ & 0 & $(0 \%)$ & 1.00 \\
\hline Prosthetic graft & 2 & $(2 \%)$ & 1 & $(5 \%)$ & 0.37 \\
\hline Blood transfusion & 15 & $(13 \%)$ & 12 & $(63 \%)$ & $<0.01$ \\
\hline Blood transfusion units $\geq 2$ & 12 & $(10 \%)$ & 10 & $(53 \%)$ & $<0.01$ \\
\hline \multicolumn{6}{|l|}{ Postoperative outcomes } \\
\hline Overall morbidity & 73 & $(63 \%)$ & 12 & $(63 \%)$ & 0.38 \\
\hline Severe morbidity & 32 & $(28 \%)$ & 8 & $(43 \%)$ & 0.28 \\
\hline Mortality & 2 & $(2 \%)$ & 4 & $(21 \%)$ & $<0.01$ \\
\hline PSCs & 57 & $(50 \%)$ & 14 & $(74 \%)$ & 0.08 \\
\hline Clinical relevant POPF & 26 & $(23 \%)$ & 7 & $(37 \%)$ & 0.24 \\
\hline Bile leak & 2 & $(2 \%)$ & 1 & $(5 \%)$ & 0.37 \\
\hline Hemorrhage & 8 & $(7 \%)$ & 3 & $(16 \%)$ & 0.19 \\
\hline DGE & 48 & $(42 \%)$ & 11 & $(58 \%)$ & 0.22 \\
\hline Relaparotomy & 5 & $(4 \%)$ & 3 & $(16 \%)$ & 0.09 \\
\hline Length of hospital stay (day), mean $( \pm$ SD) & 17 & $( \pm 8)$ & 25 & $( \pm 27)$ & 0.04 \\
\hline 90 days readmission & 17 & $(15 \%)$ & 4 & $(21 \%)$ & 0.50 \\
\hline
\end{tabular}

MPD: Main pancreatic duct; LVR: lateral venous resection; SVR: segmental venous resection; PSCs: pancreatic specific complications; POPF: postoperative pancreatic fistula; DGE: delayed gastric empty.

Impact of the center's volume (comparison of the two groups). Univariate analyses between the high volume center group and the low volume center group are summarized in Table III. According to the histopathological findings, only the perineural invasion rate was significantly higher in the high volume center group than in the low volume center group ( $82 \%$ vs. $47 \%, p=0.01$ ). Mean operative time was significantly longer in the high-volume center group (481 $( \pm 172)$ minutes vs. $397( \pm 108)$ minutes, $p<0.01)$. Both SVR $(82 \%$ vs. $47 \%, p<0.01)$ and total venous clamping $(90 \%$ vs. 
$47 \%, p<0.01)$ rates were significantly higher in the high volume center group than in the low volume center group. The intraoperative blood transfusion rate $(36 \%$ vs. $13 \%$, $p<0.01)$ and intraoperative blood transfusion unit requirement $\geq 2$ rate $(53 \%$ vs. $10 \%, p<0.01)$ were significantly higher in the low volume center group.

The mortality rate was significantly higher in the low-volume center group than in the high volume center group (21\% vs. $2 \%$, $p<0.01)$. Although there were no significant differences, a trend was noted towards an increase in the severe morbidity (43\% vs. $28 \%, p=0.28)$ and relaparotomy $(16 \% v s .4 \%, p=0.09)$ rates in the low-volume center group compared to the high volume center group. The mean length of hospital stay was significantly higher in the low volume center group than in the high volume center group (25 $( \pm 27)$ days $v s .17( \pm 8)$ days, $p=0.04)$.

Multivariate analyses (Table IV) identified the higvolume center group to be the only independent protective factor against death $(\mathrm{OR}=0.04,95 \% \mathrm{CI}(0.01-0.38), p<0.01)$ and reduced length of hospital stay (OR $<0.01,95 \mathrm{CI} \%(0.00$ $0.43), p=0.03)$. A soft pancreatic gland texture was the only independent predictive factor of severe morbidity $(\mathrm{OR}=3.57$, 95CI\% (1.43-8.92), $p<0.01)$.

\section{Discussion}

Although recent advances in surgical techniques and perioperative cares have resulted in a mortality rate below $5 \%$ for pancreatic surgery (37-40), the morbidity rate remains high, ranging from 20 to $60 \%$, including $20 \%$ to $30 \%$ Clavien-Dindo grade 3 to 4 complications (41-45). There is strong evidence that the center's volume in pancreatic surgery and the team focus on, remain an important determinant of overall mortality and postoperative courses (24-30), and recent studies have reported increased morbidity for patients undergoing PD with PV/SMVresection $(6,22,23)$. In our study, we collected a prospective series of PD with PV/SMV-resection for locally advanced PDAC. The overall mortality and morbidity rates were $4 \%$ and $63 \%$, respectively, including 30\% Clavien-Dindo grade 3 to 4 complications, and were in accordance to the literature. We showed that, over the last decade, there were no significant differences between the two periods according to the postoperative course. However, we showed that a high volume center regarding pancreatic surgery and venous resection was identified as the only independent protective factor for death and shorter length of hospital stay.

Preoperative management. In our study, $51 \%$ of patients underwent preoperative biliary stenting. The preoperative biliary stenting rate was significantly higher in period 2 than in period 1 , but did not differ between high volume centers and low volume centers. These results relate to recent changes in the preoperative management of patients who present
Table IV. Diagnostic value of clinical and surgical factors of death, severe morbidity, pancreatic specific complications, relaparotomy and hospital length of stay greater than 3 weeks.

\begin{tabular}{lccc}
\hline & Odd Ratio & $95 \%$ CI & $p$-Value \\
\hline Mortality & & & \\
$\quad$ High volume center group & 0.04 & $(0.01-0.38)$ & $<0.01$ \\
$\quad$ Soft pancreatic gland texture & 0.58 & $(0.07-4.63)$ & 0.61 \\
$\quad$ LVR & 0.57 & $(0.07-4.39)$ & 0.59 \\
Severe morbidity & & & \\
$\quad$ High volume center group & 0.79 & $(0.25-2.49)$ & 0.69 \\
$\quad$ Soft pancreatic gland texture & 3.57 & $(1.43-8.92)$ & $<0.01$ \\
$\quad$ LVR & 0.81 & $(0.31-2.13)$ & 0.67 \\
Pancreatic specific complications & & & \\
$\quad$ High volume center group & 0.40 & $(0.12-1.31)$ & 0.13 \\
$\quad$ Soft pancreatic gland texture & 1.79 & $(0.71-4.50)$ & 0.23 \\
$\quad$ LVR & 0.87 & $(0.36-2.06)$ & 0.75 \\
Relaparotomy & & & \\
$\quad$ High volume center group & 0.52 & $(0.10-2.87)$ & 0.45 \\
$\quad$ Soft pancreatic gland texture & 3.36 & $(0.70-16.04)$ & 0.13 \\
$\quad$ LVR & 2.96 & $(0.63-13.83)$ & 0.17 \\
Hospital length of stay greater & & & \\
than 3 weeks & & & \\
$\quad$ High volume center group & $<0.01$ & $(0.00-0.43)$ & 0.03 \\
$\quad$ Soft pancreatic gland texture & 88.17 & $(0.40-19348.54)$ & 0.11 \\
LVR & 0.03 & $(0.00-5.81)$ & 0.20 \\
\hline
\end{tabular}

LVR: Lateral venous resection.

locally advanced PDAC. A recent multicenter study showed that serum bilirubin levels greater than $300 \mu \mathrm{mol} / \mathrm{L}$ have a negative effect on survival, postoperative morbidity, and is associated with a higher rate of grade 3 and 4 according to the Clavien-Dindo classification system (46). In 2013, a literature review showed that biliary drainage was not a routine practice, and it should be recommended for patients with prolonged jaundice, biliary sepsis, renal failure or malnutrition, requiring neoadjuvant therapy before surgery (47).

Surprisingly, we observed that only one third of patients received neoadjuvant treatment when venous invasion was detected intraoperatively. Improvements in PDAC CT-scan evaluations by radiologists might lead to a higher initial staging detection rate of venous involvement. Thus, an increase in patients who received neoadjuvant treatment should have been noted in period 2 . We hypothesized that, during the period of inclusion, limited venous invasion $\left(<180^{\circ}\right)$ detected by CT scan was not an indication of neoadjuvant treatment; nowadays, we observe that neoadjuvant treatment is used to avoid up-front surgery in patients with limited venous contact (13).

Neoadjuvant therapy, using a single drug or a combination of drugs, with or without radiation, has been proposed to increase the proportion of resectable tumors and decrease the 
rate of margin-positive resection, as well as nodal and venous invasion $(23,48-54)$. Several studies have shown that a high percentage of patients who underwent surgery after neoadjuvant FOLFIRINOX therapy had an R0 resection (5557). Recently, current national treatment guidelines for locally advanced PDAC incorporate neoadjuvant therapy, including chemotherapy and chemo-radiation $(12,58-60)$. FOLFIRINOX was the main neoadjuvant regimen in period 2 , and was used significantly more often in period 2 than in period 1 , reflecting recent changes in the preoperative oncological management of patients who present with locally advanced PDAC.

Surgery and postoperative course. Our study is the first to assess the effects of the center's volume on the postoperative course in patients undergoing PD with PV/SMV-resection for locally advanced PDAC. Over the last 10 years, there were no significant differences between the two periods according to postoperative course. According to the volume center groups, our study showed that a high volume of pancreatic surgery and vascular resection was identified as the only independent protective factor against death and shorter length of hospital stay. Indeed, we observed a dramatic difference in the mortality rate between centers according to the volume $(21 \% v s .2 \%, p<0.01)$. Our arbitrary criteria of more or fewer than five PV/SMV-resections seemed to be relevant and should be an indicator to discriminate centers authorized to perform vascular resection during pancreatic surgery. We supported the notion that, to be certificated to perform pancreatic surgery, pancreatic centers have to be skilled with venous resection/reconstruction given that venous involvement should not be systematically detected preoperatively. However, validation with a larger series is needed to confirm our findings.

Histopathological findings. There were no significant differences in tumor size and nodal status. Only the perineural invasion rate was significantly higher in period 2 and in the high volume center group. The high perineural involvement rate, both in period 2 and the high volume center group, were probably due to advances in the technical aspects of histopathological analysis. Over the last decade, histopathology teams looking for perineural involvement have developed an increased awareness of this issue, and the histological criteria constitute a negative predictor for overall survival. Several studies observed an $\mathrm{R} 1$ resection rate for pancreatic cancer ranging from $14 \%$ to $85 \%$ in patients who underwent PD with PV/SMV-resection, because of differing definitions of tumor invasion $(6,23,33)$. Furthermore, a greater margin of clearance of at least $1.5 \mathrm{~mm}$ as a definition of $\mathrm{R} 1$ resection has been shown to further strengthen the predictive value for survival of the residual margin status $(35,36)$. In our study, a positive margin was defined as a tumor present within $1.5 \mathrm{~mm}(35,36)$. Within the entire cohort, the R1 margin resection and venous wall invasion rates were $60 \%$ and $45 \%$, respectively, and were in accordance with the literature. No significant differences were noted between the two periods and the two groups.

Our study suggests that patients with locally advanced PDAC who would potentially be suitable for surgery must be referred to a high volume center with a team focused on pancreatic surgery and venous resection to improve early postoperative outcomes. A minimum of five venous resections per year seems to be relevant to dramatically reduce postoperative mortality if PV/SMV-resection/ reconstruction is needed.

\section{References}

1 Ferlay J, Shin HR, Bray F, Forman D, Mathers C and Parkin DM: GLOBOCAN 2008 v2.0, Cancer Incidence and Mortality Worldwide. International Agency for Research on Cancer, Lyon, France. Available at http://globocan.iarc.fr/factsheet.asp (last accessed 12 June 2012).

2 Bilimoria KY, Bentrem DJ, Ko CY, Stewart AK, Winchester DP and Talamonti MS: National failure to operate on early stage pancreatic cancer. Ann Surg 246: 173-180, 2007.

3 Neoptolemos JP, Stocken DD, Bassi C, Ghaneh P, Cunningham D, Goldstein D, Padbury R, Moore MJ, Gallinger S, Mariette C, Wente MN, Izbicki JR, Friess H, Lerch MM, Dervenis C, Oláh A, Butturini G, Doi R, Lind PA, Smith D, Valle JW, Palmer DH, Buckels JA, Thompson J, McKay CJ, Rawcliffe CL and Büchler MW: Adjuvant chemotherapy with fluorouracil plus folinic acid vs. gemcitabine following pancreatic cancer resection: a randomized controlled trial. JAMA 304: 1073-1081, 2010.

4 Oettle H, Neuhaus P, Hochhaus A, Hartmann JT, Gellert K, Ridwelski K Niedergethmann M, Zülke C, Fahlke J, Arning MB, Sinn M, Hinke A and Riess H: Adjuvant chemotherapy with gemcitabine and long-term outcomes among patients with resected pancreatic cancer: the CONKO-001 randomized trial. JAMA 310: 1473-1481, 2013.

5 Regine WF, Winter KA, Abrams R, Safran H, Hoffman JP, Konski A, Benson AB, Macdonald JS, Rich TA and Willett CG: Fluorouracil-based chemoradiation with either gemcitabine or fluorouracil chemotherapy after resection of pancreatic adenocarcinoma: 5-year analysis of the U.S. Intergroup/RTOG 9704 phase III trial. Ann Surg Oncol 18: 1319-1326, 2011.

6 Giovinazzo F, Turri G, Katz MH, Heaton N and Ahmed I: Metaanalysis of benefits of portal-superior mesenteric vein resection in pancreatic resection for ductal adenocarcinoma. Br J Surg 103: 179-191, 2016.

7 Yu J, Blackford AL, Dal Molin M, Wolfgang CL and Goggins M: Time to progression of pancreatic ductal adenocarcinoma from low-to-high tumour stages. Gut 64: 1783-1789, 2015.

8 Kneuertz PJ, Cunningham SC, Cameron JL, Torrez S, Tapazoglou N, Herman JM, Makary MA, Eckhauser F, Wang J, Hirose K, Edil BH, Choti MA, Schulick RD, Wolfgang CL and Pawlik TM: Palliative surgical management of patients with unresectable pancreatic adenocarcinoma: trends and lessons learned from a large, single institution experience. J Gastrointest Surg 15: 1917-1927, 2011. 
9 Spanheimer PM, Cyr AR, Liao J, Johlin FC, Hoshi H, Howe JR and Mezhir JJ: Complications and survival associated with operative procedures in patients with unresectable pancreatic head adenocarcinoma. J Surg Oncol 109: 697-701, 2014.

10 Sanjeevi S, Ivanics T, Lundell L, Kartalis N, Andrén-Sandberg A, Blomberg J, Del Chiaro M and Ansorge C: Impact of delay between imaging and treatment in patients with potentially curable pancreatic cancer. Br J Surg 103: 267-275, 2016.

11 Werner J, Combs SE, Springfeld C, Hartwig W, Hackert T and Büchler MW: Advanced-stage pancreatic cancer: therapy options. Nat Rev Clin Oncol 10: 323-333, 2013.

12 Bockhorn M, Uzunoglu FG, Adham M, Imrie C, Milicevic M, Sandberg AA, Asbun HJ, Bassi C, Büchler M, Charnley RM, Conlon K, Cruz LF, Dervenis C, Fingerhutt A, Friess H, Gouma DJ, Hartwig W, Lillemoe KD16, Montorsi M, Neoptolemos JP, Shrikhande SV, Takaori K, Traverso W, Vashist YK, Vollmer C, Yeo CJ and Izbicki JR: Borderline resectable pancreatic cancer: A consensus statement by the International Study Group of Pancreatic Surgery (ISGPS). Surgery 155: 977-988, 2014.

13 Delpero JR, Boher JM, Sauvanet A, Le Treut YP, Sa-Cunha A, Mabrut JY, Chiche L, Turrini O, Bachellier $\mathrm{P}$ and Paye F: Pancreatic adenocarcinoma with venous involvement: is up-front synchronous portal-superior mesenteric vein resection still justified? A survey of the Association Française de Chirurgie. Ann Surg Oncol 22: 1874-1883, 2015.

14. Chua TC and Saxena A: Extended pancreaticoduodenectomy with vascular resection for pancreatic cancer: a systematic review. J Gastrointest Surg 14: 1442-1452, 2010.

15 Banz VM, Croagh D, Coldham C, Tanière P, Buckels J, Isaac J, Mayer D, Muiesan P, Bramhall S and Mirza DF: Factors influencing outcome in patients undergoing portal vein resection for adenocarcinoma of the pancreas. Eur J Surg Oncol 38: 7279, 2012.

16 Tseng JF, Raut CP, Lee JE, Pisters PW, Vauthey JN, Abdalla EK, Gomez HF, Sun CC, Crane CH, Wolff RA and Evans DB: Pancreaticoduodenectomy with vascular resection: margin status and survival duration. J Gastrointest Surg 8: 935-949, 2004.

17 Tang D, Zhang JQ and Wang DR: Long term results of pancreatectomy with portal-superior mesenteric vein resection for pancreatic carcinoma: a systematic review. Hepatogastroenterology 58: 623-631, 2011.

18 Martin RC, Scoggins CR, Egnatashvili V, Staley CA, McMasters KM and Kooby DA: Arterial and venous resection for pancreatic adenocarcinoma: operative and long-term outcomes. Arch Surg 144: 154-159, 2009.

19 Yekebas EF, Bogoevski D, Cataldegirmen G, Kunze C, Marx A, Vashist YK, Schurr PG, Liebl L, Thieltges S, Gawad KA, Schneider C and Izbicki JR: En bloc vascular resection for locally advanced pancreatic malignancies infiltrating major blood vessels: perioperative outcome and long-term survival in 136 patients. Ann Surg 247: 300-309, 2008.

20 Ravikumar R, Sabin C, Abu Hilal M, Bramhall S, White S, Wigmore S, Imber CJ and Fusai G: Portal vein resection in borderline resectable pancreatic cancer: A United Kingdom multicenter study. J Am Coll Surg 218: 401-411, 2014.

21 Allema JH, Reinders ME, van Gulik TM, van Leeuwen DJ, de Wit LT, Verbeek PC and Gouma DJ: Portal vein resection in patients undergoing pancreatoduodenectomy for carcinoma of the pancreatic head. Br J Surg 81: 1642-1646, 1994.
22 Al-Haddad M, Martin JK, Nguyen J, Pungpapong S, Raimondo M, Woodward T, Kim G, Noh K and Wallace MB: Vascular resection and reconstruction for pancreatic malignancy: a single center survival study. J Gastrointest Surg 11: 1168-1174, 2007.

23 Siriwardana HP and Siriwardena AK: Systematic review of outcome of synchronous portal-superior mesenteric vein resection during pancreatectomy for cancer. Br J Surg 93: 662-673, 2006.

24 Begg CB, Cramer LD, Hoskins WJ and Brennan MF: Impact of hospital volume on operative mortality for major cancer surgery. JAMA 280: 1747-1741, 1996.

25 Birkmeyer JD, Finlayson SR, Tosteson AN, Sharp SM, Warshaw AL and Fisher ES: Effect of hospital volume on in-hospital mortality with pancreaticoduodenectomy. Surgery 125: 250-256, 1999.

26 Kotwall CA, Maxwell JG, Brinker CC, Koch GG and Covington DL: National estimates of mortality rates for radical pancreaticoduodenectomy in 25,000 patients. Ann Surg Oncol 9: 847-854, 2002.

27 Finlayson EV and Birkmeyer JD: Effects of hospital volume on life expectancy after selected cancer operations in older adults: a decision analysis. J Am Coll Surg 196: 410-417, 2003.

28 Fong Y, Gonen M, Rubin D, Radzyner M, Radzyner M and Brennan MF: Long-term survival is superior after resection for cancer in high-volume centers. Ann Surg 242: 540-544, 2005.

29 Birkmeyer JD, Stukel TA, Siewers AE, Goodney PP, Wennberg DE and Lucas FL: Surgeon volume and operative mortality in the United States. N Engl J Med 349: 2117-2127, 2003.

30 Schmidt CM, Turrini O, Parikh P, House MG, Zyromski NJ, Nakeeb A, Howard TJ, Pitt HA and Lillemoe KD: Effect of hospital volume, surgeon experience, and surgeon volume on patient outcomes after pancreaticoduodenectomy. Arch Surg 145: 634-640, 2010.

31 Sanjay P, Takaori K, Govil S, Shrikhande SV and Windsor JA: "Artery-first" approaches to pancreatoduodenectomy. Br J Surg 99: 1027-1035, 2012.

32 Edge SB and Compton CC: The American Joint Committee on Cancer: the 7th edition of the AJCC cancer staging manual and the future of TNM. Ann Surg Oncol 17: 1471-1474, 2010.

33 Verbecke CS and Menon KV: Redefining resection margin status in pancreatic cancer. HPB 11: 282-289, 2009.

34 The Royal College of Pathologists. Standards and datasets for reporting cancers. Minimum dataset for the histopathological reporting of pancreatic, ampulla of vater and bile duct carcinoma. London, UK: The Royal College of Pathologists; 2002.

35 Chang DK, Johns AL, Merrett ND, Gill AJ, Colvin EK, Scarlett CJ, Nguyen NQ, Leong RW, Cosman PH, Kelly MI, Sutherland RL, Henshall SM, Kench JG and Biankin AV: Margin clearance and outcome in resected pancreatic cancer. J Clin Oncol 27: 2855-2862, 2009.

36 Jamieson NB, Chan NI, Foulis AK, Dickson EJ, McKay CJ and Carter CR: The prognostic influence of resection margin clearance following pancreaticoduodenectomy for pancreatic ductal adenocarcinoma. J Gastrointest Surg 17: 511-521, 2013.

37 Yeo CJ, Cameron JL, Sohn TA, Lillemoe KD, Pitt HA, Talamini MA, Hruban RH, Ord SE, Sauter PK, Coleman J, Zahurak ML, Grochow LB and Abrams RA: Six hundred fifty consecutive pancreaticoduodenectomies in the 1990s: pathology, complications, and outcomes. Ann Surg 226: 248-260, 1997.

38 Bassi C, Falconi M, Salvia R, Mascetta G, Molinari E and Pederzoli P: Management of complications after pancreaticoduodenectomy in a high volume centre: results on 150 consecutive patients. Dig Surg 18: 453-458, 2001. 
39 Fong ZV, Ferrone CR, Thayer SP, Wargo JA, Sahora K, Seefeld KJ, Warshaw AL, Lillemoe KD, Hutter MM and Fernández-Del Castillo C: Understanding hospital readmissions after pancreaticoduodenectomy: can we prevent them? A 10-year contemporary experience with 1,173 patients at the Massachusetts general hospital. J Gastrointest Surg 18: 137144, 2014

40 McPhee JT, Hill JS, Whalen GF, Zayaruzny M, Litwin DE, Sullivan ME, Anderson FA and Tseng JF: Perioperative mortality for pancreatectomy: a national perspective. Ann Surg 246: 246253, 2007.

41 Cavell LK, Allen PJ, Vinoya C, Eaton AA, Gonen M, Gerdes H, Mendelsohn RB, D'Angelica MI, Kingham TP, Fong Y, Dematteo R, Jarnagin WR, Kurtz RC and Schattner MA: Biliary selfexpandable metal stents do not adversely affect pancreaticoduodenectomy. Am J Gastroenterol 108: 1168-1173, 2013.

42 Squires MH, Mehta VV, Fisher SB, Lad NL, Kooby DA, Sarmiento JM, Cardona K, Russell MC, Staley CA 3rd and Maithel SK: Effect of preoperative renal insufficiency on postoperative outcomes after pancreatic resection: a single institution experience of 1,061 consecutive patients. J Am Coll Surg 218: 92-101, 2014.

43 Büchler MW, Wagner M, Schmied BM, Uhl W, Friess H and Z'graggen $\mathrm{K}$ : Changes in morbidity after pancreatic resection: toward the end of completion pancreatectomy. Arch surg 138 : 1310-1314, 2003.

44 Van Heek NT, Kuhlmann KF, Scholten RJ, de Castro SM, Busch OR, van Gulik TM Obertop H and Gouma DJ: Hospital volume and mortality after pancreatic resection: a systematic review and an evaluation of intervention in the Netherlands. Ann Surg 242: 781-788, 2005.

45 Wellner UF, Makowiec F, Sick O, Hopt UT and Keck T: Arguments for an individualized closure of the pancreatic remnant after distal pancreatic resection. World J Gastrointest Surg 27: 114-120, 2012.

46 Sauvanet A, Boher J, Paye F, Bachellier P, Sa Cuhna A, Le Treut YP, Adham M, Mabrut JY, Chiche L and Delpero JR: the French Association of Surgery. Severe jaundice increases early severe morbidity and decreases long-term survival after pancreaticoduodenectomy for pancreatic adenocarcinoma. J Am Coll Surg 221: 380-389, 2015.

47 Iacono C, Ruzzenente A, Campagnaro T, Bortolasi L, Valdegamberi A and Guglielmi A: Role of preoperative biliary drainage in jaundiced patients who are candidates for pancreatoduodenectomy or hepatic resection. Ann Surg 257: 191-204, 2013.

48 Chun YS, Milestone BN, Watson JC, Cohen SJ, Burtness B, Engstrom PF, Haluszka O, Tokar JL, Hall MJ, Denlinger CS, Astsaturov I and Hoffman JP: Defining venous involvement in borderline resectable pancreatic cancer. Ann Surg Oncol 17: 2832-2838, 2010.

49 McClaine RJ, Lowy AM, Sussman JJ, Schmulewitz N, Grisell DL and Ahmad SA: Neoadjuvant therapy may lead to successful surgical resection and improved survival in patients with borderline resectable pancreatic cancer. HPB 12: 73-79, 2010.

50 Gillen S, Schuster T, Meyer Zum Buschenfelde C, Friess H and Kleeff J: Preoperative neoadjuvant therapy in pancreatic cancer: a systematic review and meta- analysis of response and resection percentages. PLoS Med 7: e1000267, 2010.

51 Andriulli A, Festa V, Botteri E, Valvano MR, Koch M, Bassi C, Maisonneuve P and Sebastiano PD: Neoadjuvant preoperative gemcitabine for patients with localized pancreatic cancer: a meta- analysis of prospective studies. Ann Surg Oncol 19: 16441662, 2012.

52 Rose JB, Rocha FG, Alseidi A, Biehl T, Moonka R, Ryan JA, Lin B, Picozzi V and Helton S: Extended neoadjuvant chemotherapy for borderline resectable pancreatic cancer demonstrates promising postoperative outcomes and survival. Ann Surg Oncol 21: 1530-1537, 2014.

53 Heinemann V, Haas M and Boeck S: Neoadjuvant treatment of borderline resectable and non-resectable pancreatic cancer. Ann Oncol 24: 2484-2492, 2013.

54 Katz MH, Wang H, Balachandran A, Bhosale P, Crane CH, Wang X Pisters PW, Lee JE, Vauthey JN, Abdalla EK, Wolff R, Abbruzzese J, Varadhachary G, Chopin-Laly X, Charnsangavej $\mathrm{C}$ and Fleming JB: Effect of neoadjuvantchemoradiation and surgical technique on recurrence of localized pancreatic cancer. J Gastrointest Surg 16: 68-78, 2012.

55 Christians KK, Tsai S, Mahmoud A, Ritch P, Thomas JP, Wiebe L, Kelly T, Erickson B, Wang H, Evans DB and George B: Neoadjuvant FOLFIRINOX for borderline resectable pancreas cancer: a new treatment paradigm? Oncologist 19: 266-274, 2014.

56 Conroy T, Desseigne F, Ychou M, Bouché O, Guimbaud R, Bécouarn Y, Adenis A, Raoul JL, Gourgou-Bourgade S, de la Fouchardière C, Bennouna J, Bachet JB, Khemissa-Akouz F, Péré-Vergé D, Delbaldo C, Assenat E, Chauffert B, Michel P, Montoto-Grillot $\mathrm{C}$ and Ducreux M: FOLFIRINOX versus gemcitabine for metastatic pancreatic cancer. N Engl J Med 364: 1817-1825, 2011.

57 Ferrone CR, Marchegiani G, Hong TS, Ryan DP, Deshpande V, McDonnell EI, Sabbatino F, Santos DD, Allen JN, Blaszkowsky LS, Clark JW, Faris JE, Goyal L, Kwak EL, Murphy JE, Ting DT, Wo JY, Zhu AX, Warshaw AL, Lillemoe KD and Fernández-del Castillo C: Radiological and surgical implications of neoadjuvant treatment with FOLFIRINOX for locally advanced and borderline resectable pancreatic cancer. Ann Surg 261: 12-17, 2015.

58 National Comprehensive Cancer Network. NCCN practice guidelines for pancreatic cancer, version 2, 2012. Available at http://www.nccn.org/professionals/physician_gls/recently_ updated. Asp.

59 Callery MP, Chang KJ, Fishman EK, Talamonti MS, William Traverso L and Linehan DC: Pretreatment assessment of resectable and borderline resectable pancreatic cancer: Expert consensus statement. Ann Surg Oncol 16: 1727-1733, 2009.

60 Evans DB, Farnell MD, Lillemoe KD, Vollmer C Jr., Strasberg SM and Schulick RD: Surgical treatment of resectable and borderline resectable pancreas cancer: expert consensus statement. Ann Surg Oncol 16: 1736-1744, 2009.

61 Raman SP, Reddy S, Weiss MJ, Manos LL, Cameron JL, Zheng L, Herman JM, Hruban RH, Fishman EK and Wolfgang CL: Impact of the time interval between MDCT imaging and surgery on the accuracy of identifying metastatic disease in patients with pancreatic cancer. Am J Roentgenol 204: W37-W42, 2015. 